\title{
Determination of trace heavy metals in milk using an ionic liquid and bismuth oxide nanoparticles modified carbon paste electrode
}

\author{
PING JianFeng, WU Jian* \& YING YiBin \\ College of Biosystems Engineering and Food Science, Zhejiang University, Hangzhou 310058, China
}

Received July 23, 2011; accepted December 9, 2011; published online April 12, 2012

\begin{abstract}
A novel carbon composite electrode modified with bismuth oxide nanoparticles and the ionic liquid $n$-octylpyridinium hexafluorophosphate was fabricated and used to simultaneously determine cadmium and lead levels using square wave anodic stripping voltammetry. This electrode combines the unique advantages of nanomaterials and ionic liquid with the low cost and easy fabrication of the carbon composite electrode. Compared with the traditional binder based composite electrode, our electrode exhibited well-defined and separate stripping voltammetric peaks for cadmium and lead. Furthermore, the antifouling capacity of the bismuth film electrode was significantly improved by the ionic liquid. Under optimized conditions, the linear range of the composite electrode was from 3.0 to $30.0 \mu \mathrm{g} \mathrm{L}{ }^{-1}$ for both metal ions with a detection limit of $0.15 \mu \mathrm{g} \mathrm{L}^{-1}$ for cadmium and $0.21 \mu \mathrm{g} \mathrm{L} \mathrm{L}^{-1}$ for lead. Trial milk sample analyses showed that the modified electrode was sensitive, reliable and effective for the determination of trace heavy metals, holding great promise for routine analysis applications.
\end{abstract}

heavy metals, bismuth oxide nanoparticles, ionic liquid, carbon paste electrode, milk

Citation: $\quad$ Ping J F, Wu J, Ying Y B. Determination of trace heavy metals in milk using an ionic liquid and bismuth oxide nanoparticles modified carbon paste electrode. Chin Sci Bull, 2012, 57: 1781-1787, doi: 10.1007/s11434-012-5115-1

In recent years, there has been an increasing demand to assess the damage caused by heavy metal pollution [1,2]. This pollution, which arises from industrialization, has led to a variety of problems for land-use, in groundwater, and terrestrial and aquatic ecosystems [3]. Heavy metals accumulate in the food chain, so all foodstuffs, especially products of animal origin, become unsafe as heavy metal pollution increases [4,5]. Milk is an important food of animal origin; it has most of the nutrients necessary for a healthy diet, and is an important food for some consumer groups, such as infants and the elderly. Therefore, the determination of levels of toxic heavy metals in milk is of great importance.

The traditional procedure for heavy metal determination is based on spectroscopic methods, such as atomic absorption spectrometry and X-ray fluorescence spectrometry $[6,7]$. These methods, however, require complex sample pretreatment processes and expensive instrumentation and are therefore not ideal for routine applications [8]. Thus, the

*Corresponding author (email: wujian69@zju.edu.cn) development of a sensitive and simple method for the rapid evaluation of heavy metals levels is highly desirable for environmental monitoring and food safety applications. Electrochemical methods, especially electrochemical stripping analysis (ESA), are widely recognized as a powerful tool for the simultaneous determination of multiple types of metal ion, because of the combination of an effective preconcentration step with advanced electrochemical measurements of the accumulated analytes [5,9]. ESA instruments are portable, compact and inexpensive compared to spectroscopic equipment, and are thus practical for on-site measurements for biomedical, environmental and industrial monitoring [10].

Mercury electrodes have high reproducibility and sensitivity, are therefore preferred for stripping analysis [11]. However, the toxicity of mercury makes it undesirable for certain sensing applications, particularly those involving food contact. Considerable efforts have been made to find suitable alternative electrode materials for stripping analysis. Recently, bismuth film electrodes (BiFEs) have been 
proposed in view of their low toxicity and comparable performance to mercury [12-15]. There are two methods for the preparation of the bismuth film: in situ and ex situ plating. However, the deposition conditions of these methods must be carefully controlled to obtain proper analytical performance, especially in the in situ film generation technique $[16,17]$. Moreover, BiFEs have a serious limitation because of insufficient adhesion of the film to the electrode surface which causes degradation of the electrode [18].

Chemically modified carbon paste electrodes (CPEs) are cheap, easy to make, and have a low background current, and so have been incorporated into BiFEs [19,20]. Metallic bismuth or bismuth precursors have been successfully employed to modify CPEs for stripping analysis [19-22]. However, the inherent disadvantages of CPEs such as low mechanical stability and reproducibility limit their practical application. Moreover, the use of nonconductive binders such as paraffin oil may weaken the electrochemical performance of CPEs [23]. Therefore, new electrode material developments are still needed to meet the growing demands for on-site monitoring of trace heavy metal ions.

The use of conductive solid materials as binders in CPEs to replace traditional binder systems shows promise to improve performance [24]. Ionic liquids (IL) [25], triphenylamine [26] and molecular wires [27], have been used to prepare CPEs with improved conductivity, high mechanical stability, and fast electron transfer rates. Nano-structured materials are also candidates because of their large specific surface area, good biocompatibility, and ease of preparation [28]. Nanomaterial modified CPEs exhibit many favorable characteristics for electroanalysis, including fast response, high sensitivity and selectivity $[29,30]$.

We have devised a novel carbon composite electrode modified with bismuth oxide nanoparticles (BONPs) and IL $n$-octylpyridinum hexafluorophosphate (OPFP). Such a composite electrode brings new capabilities for electrochemical devices by combining the unique advantages of nanomaterials and IL with the characteristics of a bulk composite electrode. Under the optimized conditions, our electrode exhibited good analytical performance determining cadmium ion $(\mathrm{Cd}(\mathrm{II}))$ and lead ion $(\mathrm{Pb}(\mathrm{II}))$ levels. Furthermore, the performance of the proposed electrode for $\mathrm{Cd}(\mathrm{II})$ and $\mathrm{Pb}$ (II) measuring heavy metal contamination in milk was examined in detail. This is a novel application of a BONPs and IL modified carbon composite electrode.

\section{Experimental}

\subsection{Reagents}

All chemicals were of analytical grade and used without any further purification. Bismuth oxide nanoparticles (BONPs), $99.8 \%$, particle size $90-210 \mathrm{~nm}$, were purchased from Sigma (USA). Ionic liquid $n$-octylpyridinium hexafluorophosphate (OPFP, 99.0\%) was obtained from Shanghai Chengjie
Co., Ltd. (Shanghai, China). Graphite powder (size $<30 \mu \mathrm{m}$, spectral pure grade) and paraffin oil were purchased from Sinopham Chemical Reagent Co., Ltd. (Shanghai, China). Standard solutions of $\mathrm{Bi}(\mathrm{III}), \mathrm{Cd}(\mathrm{II})$ and $\mathrm{Pb}(\mathrm{II})$ (1000 mg $\mathrm{L}^{-1}$ ) were prepared and diluted as required. An acetate buffer solution $\left(0.1 \mathrm{~mol} \mathrm{~L}^{-1}, \mathrm{pH} 4.5\right)$ was used as the supporting electrolyte. Millipore-Q $(18.2 \mathrm{M} \Omega \mathrm{cm})$ water was used for all experiments.

\subsection{Apparatus}

All the electrochemical measurements were carried out on a CHI 440 electrochemical workstation (CH Instruments, USA). The electrochemical cell was assembled with a conventional three-electrode system: a saturated $\mathrm{Ag} / \mathrm{AgCl}$ reference electrode, a Pt wire auxiliary electrode, and the prepared working electrode. Voltammetric experiments were carried out in a one-compartment $10-\mathrm{mL}$ cell. A magnetic stirrer was used to stir the test solution during the pretreatment and deposition steps. All the experiments were performed at $25 \pm 1^{\circ} \mathrm{C}$.

\subsection{Electrode preparation}

An established method [24] was used to prepare the bismuth oxide nanoparticles and ionic liquid modified carbon paste electrode (BONPs-IL-CPE). The $0.49 \mathrm{~g}$ graphite powder, $0.49 \mathrm{~g}$ OPFP and $0.02 \mathrm{~g}$ BONPs were hand-mixed in a mortar and pestle for $30 \mathrm{~min}$. A portion of the resulting paste was packed firmly into the electrode cavity $(1.8 \mathrm{~mm}$ diameter) of a glass sleeve with a spatula. The electrode was then heated in an oven to a temperature higher than the melting point of OPFP $\left(\mathrm{mp} 65^{\circ} \mathrm{C}\right)$. Electrode contact was established via a copper wire introduced into the back of the sample. For comparison, IL-CPE (without BONPs) with a $1 / 1(\mathrm{w} / \mathrm{w})$ graphite to OPFP was prepared in a similar way. The bismuth oxide nanoparticle modified traditional carbon paste electrode (BONPs-PO-CPE) was fabricated by mixing $0.02 \mathrm{~g}$ BONPs, $0.69 \mathrm{~g}$ graphite powder and $0.29 \mathrm{~g}$ paraffin oil. The working electrodes were polished using weighing paper, then washed with distilled water and dried under nitrogen atmosphere.

\subsection{Milk sample extract preparation}

Retail packaged milk was obtained from a local supermarket (Hangzhou, China). The treatment of the milk samples was performed using an established method [31]. Briefly, 6 $\mathrm{mL}$ of milk was added into $10 \mathrm{~mL}$ tubes and centrifuged at $4000 \times g$ (Thermo Scientific Biofuge Stratos, Germany) for 5 $\mathrm{min}$ and then the lipid phases were precipitated. The upper phase including lipids was removed. The lower layer containing the minerals was transferred into another tube, and $100 \mu \mathrm{L}$ of concentrated hydrochloric acid $(\mathrm{HCl})$ and $100 \mu \mathrm{L}$ of glacial acetic acid were added. Then the mixture was 
centrifuged at $6000 \times g$ for $10 \mathrm{~min}$. The supernatant including the metal ions $\mathrm{Cd}(\mathrm{II})$ and $\mathrm{Pb}$ (II) was collected and filtered at a pore size of $0.22 \mu \mathrm{m}$. Before transferring to electrochemical cells, the $\mathrm{pH}$ of the obtained extract solutions was adjusted to 4.5 by using $0.1 \mathrm{~mol} \mathrm{~L}^{-1} \mathrm{NaOH}$ solution.

\subsection{Measurement procedure}

The reduction of bismuth oxide to bismuth was performed at $-1.2 \mathrm{~V}$ (vs. $\mathrm{Ag} / \mathrm{AgCl}$ ) for $300 \mathrm{~s}$ in $0.1 \mathrm{~mol} \mathrm{~L}^{-1} \mathrm{KOH}$ solution. Square wave anodic stripping voltammetry was employed to simultaneously determine $\mathrm{Cd}(\mathrm{II})$ and $\mathrm{Pb}(\mathrm{II})$ in the buffer solution and the sample solution. The method used an electrochemical pre-concentration step usually at $-1.2 \mathrm{~V}$ for $180 \mathrm{~s}$, an equilibration period of $10 \mathrm{~s}$, and a square wave stripping scan from -1.2 to $-0.3 \mathrm{~V}$. The parameters for the square wave measurement are: square wave amplitude, 20 $\mathrm{mV}$; potential step, $5 \mathrm{mV}$; frequency, $20 \mathrm{~Hz}$. Before each measurement, a pre-condition/“clean" step at potential of $-0.3 \mathrm{~V}$ was applied for $30 \mathrm{~s}$.

\section{Results and discussion}

Figure 1(A) shows the typical cyclic voltammogram from a BONPs-IL-CPE recorded in $0.1 \mathrm{~mol} \mathrm{~L}^{-1} \mathrm{KOH}$ solution. It can be seen that two obvious reduction peaks were found at $-0.95 \mathrm{~V}$ (peak $\mathrm{C}_{1}$ ) and $-1.1 \mathrm{~V}\left(\right.$ peak $\mathrm{C}_{2}$ ) during the cathodic scan. In alkaline solution a chemical reaction between bismuth oxide and $\mathrm{OH}^{-}$occurred (eq. (1)), whilst the electrochemical reduction of $\mathrm{BiO}_{2}^{-}$occurred at $-0.95 \mathrm{~V}$ (peak $\mathrm{C}_{1}$ ) (eq. (2)) [32]. Another reduction peak $\mathrm{C}_{2}$ occurred at $-1.1 \mathrm{~V}$ represented the reduction process of $\mathrm{Bi}(\mathrm{III})$ to $\mathrm{Bi}$ (eq. (3)) [18]. Thus, the potential of $-1.2 \mathrm{~V}$, which was more negative than the reduction potential of bismuth oxide, was chosen for reducing bismuth oxide to form bismuth film at the electrode surface.

$$
\begin{aligned}
\mathrm{Bi}_{2} \mathrm{O}_{3}(\mathrm{~s})+2 \mathrm{OH}^{-} & \rightarrow 2 \mathrm{BiO}_{2}^{-}+\mathrm{H}_{2} \mathrm{O} \\
\mathrm{BiO}_{2}^{-}+2 \mathrm{H}_{2} \mathrm{O}+3 \mathrm{e} & \rightarrow \mathrm{Bi}(\mathrm{s})+4 \mathrm{OH}^{-} \\
\mathrm{Bi}_{2} \mathrm{O}_{3}(\mathrm{~s})+3 \mathrm{H}_{2} \mathrm{O}+6 \mathrm{e} & \rightarrow 2 \mathrm{Bi}(\mathrm{s})+6 \mathrm{OH}^{-}
\end{aligned}
$$

Before studying the stripping performance of the BONPs-IL-CPE, the process of hydrogen evolution at the electrode surface was investigated, since this has a profound effect on the stripping analysis results $[13,14]$. As shown in Figure 1(B), the background current of the IL-CPE increased rapidly below $-1.0 \mathrm{~V}$ (Figure 1(B)-a), whilst a pre-conditioned BONPs-IL-CPE (Figure 1(B)-b) exhibited a lower background current and more negative hydrogen evolution potential than the IL-CPE, because of the formation of a bismuth film at the electrode surface. The background of the BONPs-IL-CPE was extremely stable during the repetitive scans. These results demonstrated that the proposed composite electrode could be used to determine $\mathrm{Cd}(\mathrm{II})$ and $\mathrm{Pb}(\mathrm{II})$ with a reduction potential, more negative than $-1.2 \mathrm{~V}$.
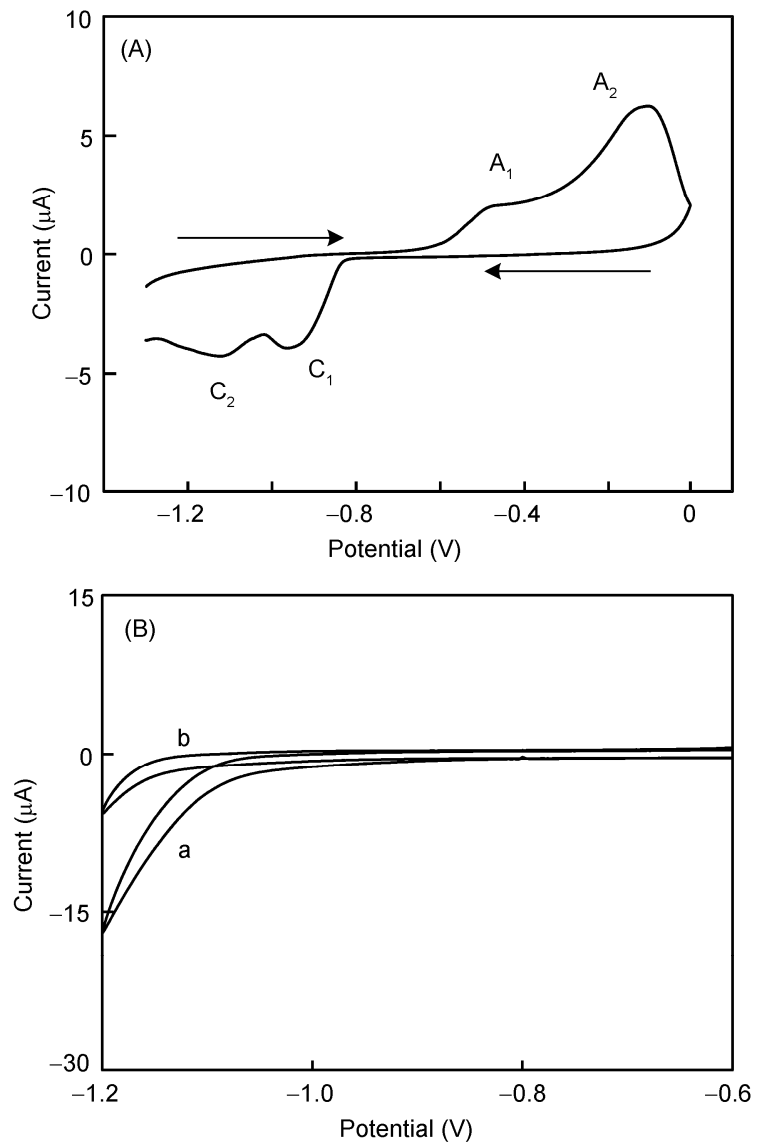

Figure 1 (A) Cyclic voltammogram of the BONPs-IL-CPE in $0.1 \mathrm{~mol}$ $\mathrm{L}^{-1} \mathrm{KOH}$ solution. (B) Cyclic voltammograms of an IL-CPE (a) and the

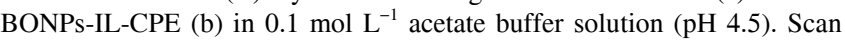
rate: $20 \mathrm{mV} \mathrm{s}^{-1}$.

Figure 2 shows the square wave anodic stripping voltammograms (SWASVs) of $30.0 \mu \mathrm{g} \mathrm{L}^{-1} \mathrm{Cd}$ (II) and $\mathrm{Pb}$ (II) at the BONPs-PO-CPE, bare IL-CPE, bismuth film modified IL-CPE (BiF/IL-CPE) and BONPs-IL-CPE. As can be seen in Figure 2 curve a, the response of the bare IL-CPE was very poor, with two small peaks. However, after the addition of BONPs into the bulk composite electrode and pretreatment in alkaline solution, the electrode exhibited high sensitivity toward $\mathrm{Cd}(\mathrm{II})$ and $\mathrm{Pb}$ (II) detection with well-defined, sharp and separate stripping peaks (Figure 2e). This phenomenon can be attributed to the fact that bismuth can form an "alloy" with $\mathrm{Cd}$ and $\mathrm{Pb}$ that more readily reduces $\mathrm{Cd}(\mathrm{II})$ and $\mathrm{Pb}(\mathrm{II})$. The peak current of $\mathrm{Cd}(\mathrm{II})$ and $\mathrm{Pb}$ (II) measured using the BONPs-IL-CPE was comparable with those of a BiF/IL-CPE (Figure 2-b), however our electrodes are easier to prepare and more stable. Furthermore, the stripping response at the BONPs-IL-CPE was better than that of BONPs-PO-CPE (Figure 2-c). This improved performance can be ascribed to the enhanced conductivity of the BONPs-IL-CPE with a conductive ionic liquid as the binder, while poor conductivity was found on the surface of the BONPs-PO-CPE using nonconductive paraffin oil as the binder [24,25]. 


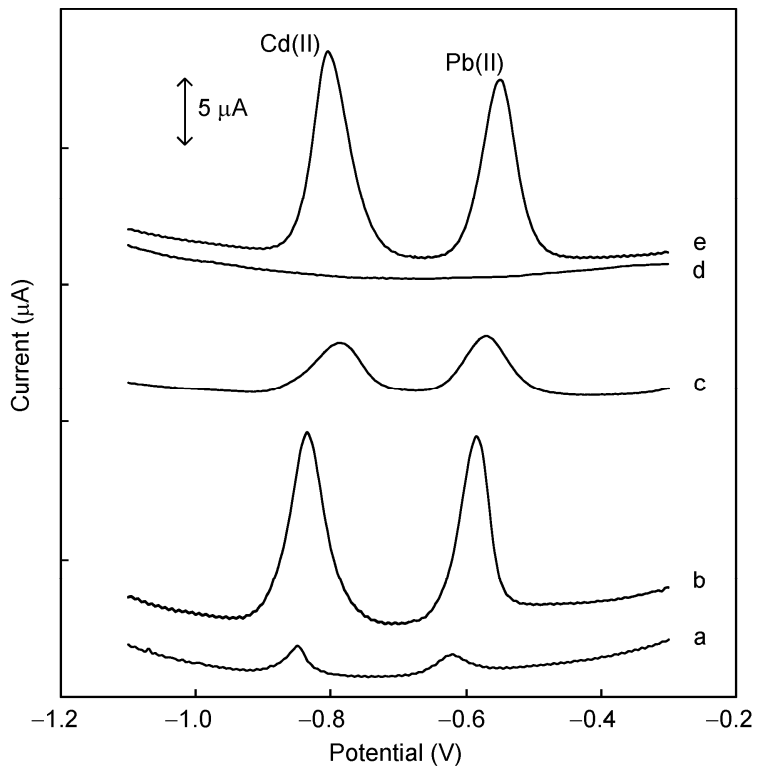

Figure 2 SWASVs of $30.0 \mu \mathrm{g} \mathrm{L}{ }^{-1} \mathrm{Cd}(\mathrm{II})$ and $\mathrm{Pb}$ (II) by different working electrodes. Curves a, IL-CPE; b, BiF/IL-CPE; c, BONPs-PO-CPE, and e, BONPs-IL-CPE. Curve $\mathrm{d}$ is the stripping response of the BONPs-IL-CPE in the absence of any metal ions. Deposition time: $180 \mathrm{~s}$. Deposition potential: -1.2 V. Supporting electrolyte: $0.1 \mathrm{~mol} \mathrm{~L}^{-1}$ acetate buffer solution ( $\mathrm{pH}$ $4.5)$

To optimize the BONPs content in the composite electrode, electrodes with different BONPs contents ranging from 0 to $5 \%(\mathrm{w} / \mathrm{w})$ were prepared. Figure 3 shows the effect of the amount of BONPs on the stripping response of $30.0 \mu \mathrm{g} \mathrm{L}^{-1} \mathrm{Cd}(\mathrm{II})$ and $\mathrm{Pb}(\mathrm{II})$. The response increased quickly with the increase of BONPs content from 0 to $2 \%$. Further increasing the BONPs content, the sensitivity of the developed composite electrode followed a decreasing trend, probably due to a decrease in conductivity of the working electrode surface. Hence, an electrode containing $2 \%$ of BONPs was used for subsequent measurements.

To further optimize the performance of the BONPs-IL$\mathrm{CPE}$ for the determination of $\mathrm{Cd}(\mathrm{II})$ and $\mathrm{Pb}(\mathrm{II})$, the deposition conditions including the deposition time and deposition

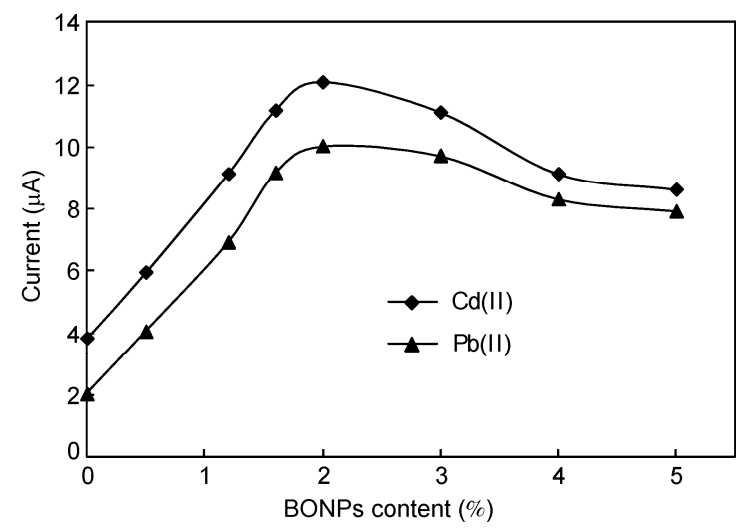

Figure 3 Effect of BONPs content on the stripping response of 30.0 $\mu \mathrm{g} \mathrm{L}{ }^{-1} \mathrm{Cd}(\mathrm{II})$ and $\mathrm{Pb}(\mathrm{II})$. Other conditions are as in Figure 2. potential were investigated. Figure 4 (A) illustrates the influence of deposition time (30 to $300 \mathrm{~s}$ ) on the stripping response of $\mathrm{Cd}(\mathrm{II})$ and $\mathrm{Pb}(\mathrm{II})$. As the deposition time increased from 30 to $180 \mathrm{~s}$, the stripping peak current of $\mathrm{Cd}(\mathrm{II})$ and $\mathrm{Pb}(\mathrm{II})$ increased linearly. However, the linear trend was not obvious with further increasing deposition time. Only a slight increase of the stripping response was found due to the saturation loading of the electrode surface. So a deposition time of $180 \mathrm{~s}$ was selected. The effect of deposition potential on the stripping peak current is shown in Figure 4 (B). When the deposition potential was $-0.8 \mathrm{~V}$, the response of $\mathrm{Cd}(\mathrm{II})$ was negligible. After applying more negative potential, the stripping peak current increased significantly. The highest peak current was achieved when the potential of $-1.2 \mathrm{~V}$ was applied. As the deposition potential further negatively shifted, both the peak currents decreased because of the reduction of certain other chemicals interfering with the determination. Furthermore, the reproducibility at these potentials was very poor because of hydrogen evolution at the electrode surface. Consequently, $-1.2 \mathrm{~V}$ was used as the optimal deposition potential for subsequent experiments.

Calibration for the simultaneous determination of $\mathrm{Cd}(\mathrm{II})$ and $\mathrm{Pb}$ (II) using square wave anodic stripping voltammetry was performed. Figure 5 illustrates the stripping response of the BONPs-IL-CPE without any cross interference as the
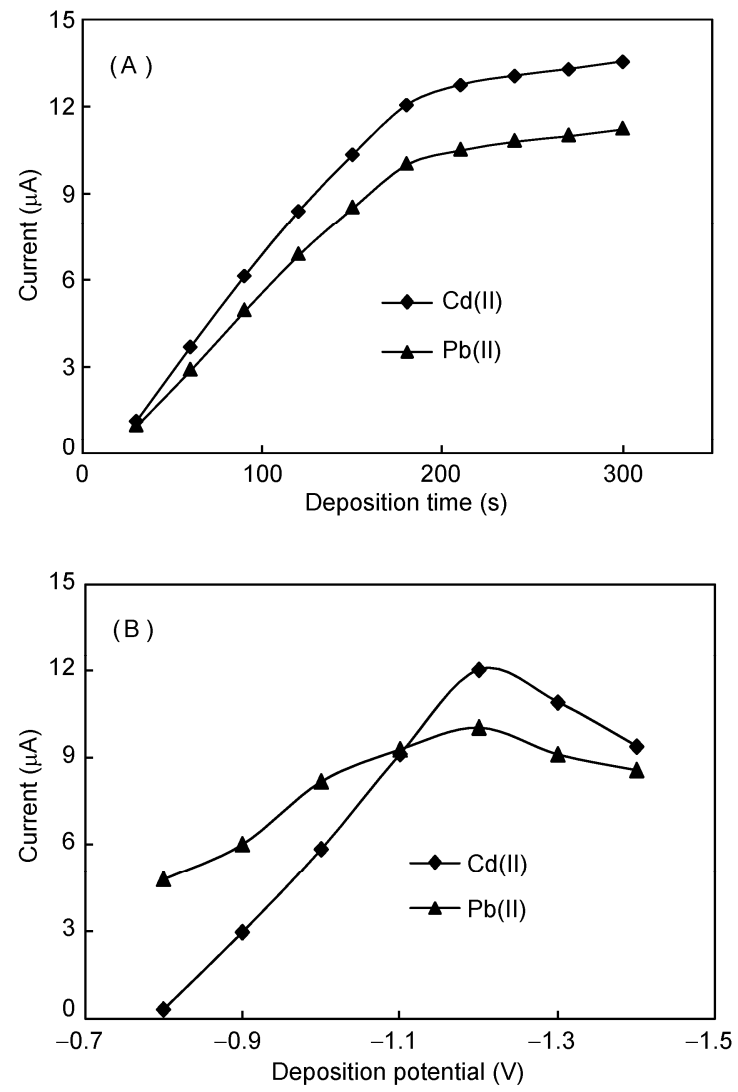

Figure 4 Effects of deposition time (A) and deposition potential (B) on the stripping response of $30.0 \mu \mathrm{g} \mathrm{L}^{-1} \mathrm{Cd}$ (II) and $\mathrm{Pb}$ (II) obtained at the BONPs-IL-CPE with a BONPs loading of $2 \%$. 


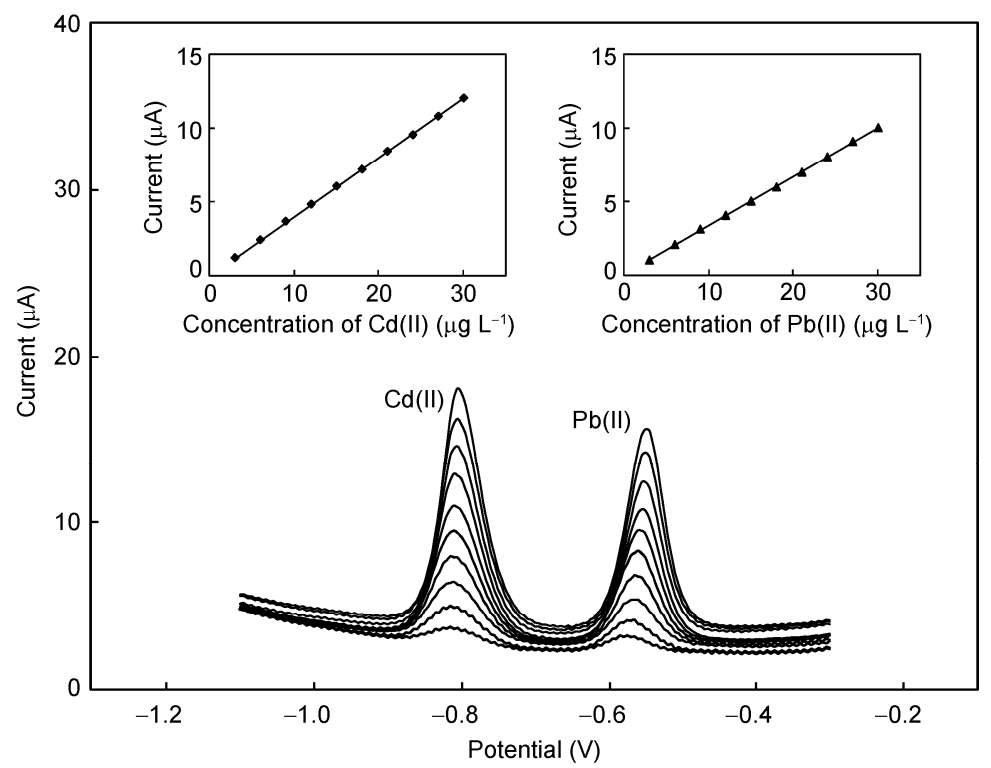

Figure 5 SWASVs for the successive additions of $\mathrm{Cd}(\mathrm{II})$ and $\mathrm{Pb}(\mathrm{II})$ in $3.0 \mu \mathrm{g} \mathrm{L} \mathrm{L}^{-1}$ steps at the BONPs-IL-CPE. Inset shows the calibration curves for the determination of $\mathrm{Cd}(\mathrm{II})$ and $\mathrm{Pb}(\mathrm{II})$. Other conditions are as in Figure 2.

concentrations of both metal ions were increased from 3.0 to $30.0 \mu \mathrm{g} \mathrm{L}^{-1}$ in $3.0 \mu \mathrm{g} \mathrm{L} \mathrm{L}^{-1}$ increments, the inset shows the corresponding calibration curves. The response was linear within the above range with linear correlation coefficients of 0.9927 and 0.9924 for $\mathrm{Cd}(\mathrm{II})$ and $\mathrm{Pb}(\mathrm{II})$, respectively. The BONPs-IL-CPE also demonstrated satisfactory detection limits $(S / N=3)$ of $0.15 \mu \mathrm{g} \mathrm{L} \mathrm{L}^{-1}$ for $\mathrm{Cd}(\mathrm{II})$ and $0.21 \mu \mathrm{g}$ $\mathrm{L}^{-1}$ for $\mathrm{Pb}(\mathrm{II})$ in combination with a $180 \mathrm{~s}$ deposition time. Lower detection limits for both metal ions could be expected by prolonging the deposition time. Repetitive measurements of $30.0 \mu \mathrm{g} \mathrm{L}^{-1} \mathrm{Cd}(\mathrm{II})$ and $\mathrm{Pb}(\mathrm{II})$ exhibited good reproducibility with relative standard deviations of $2.9 \%$ and $2.1 \%$ for $\mathrm{Cd}(\mathrm{II})$ and $\mathrm{Pb}(\mathrm{II})$, respectively $(n=10)$.

To determine the storage stability of the BONPs-IL-CPE, the electrodes were stored in air at ambient conditions, and the sensitivity was checked daily. The response of the electrode exhibited no obvious changes after $60 \mathrm{~d}$, indicating the long-term stability of the composite electrode. The operational stability of the electrode during continuous monitoring in solutions was also evaluated. When not in use, the electrode was kept in an acetate buffer solution. After each hour, the stripping response to $20 \mu \mathrm{g} \mathrm{L} \mathrm{L}^{-1}$ of $\mathrm{Cd}(\mathrm{II})$ and $\mathrm{Pb}$ (II) was recorded. As expected, no obvious changes were obtained during the $24 \mathrm{~h}$ measurement, suggesting that the composite electrode was highly stable in an aqueous phase environment.

Surface-active macromolecules have a significant effect on the stripping response of BiFEs [14-16]. The effect of different type of surfactants on the developed electrode was evaluated and compared with those of a BONPs-PO-CPE. Table 1 summarizes normalized current, $I_{\mathrm{p}} / I_{\mathrm{pmax}}$ data, observed at different concentrations of surfactants for both electrodes. It can be seen that the cationic surfactant cetyltrimethylammonium (CTAB) exhibited the most obvious decrease in the stripping currents owing to the electrostatic repulsion of $\mathrm{Cd}(\mathrm{II})$ and $\mathrm{Pb}(\mathrm{II})$. Triton $\mathrm{X}-100$ produced moderate interference on the current signal. Sodium dodecyl sulfate (SDS) which is an anionic surfactant induced the least significant decrease in stripping current. Nevertheless, compared with the BONPs-PO-CPE, it is obvious in most cases that the BONPs-IL-CPE was much more tolerant to the presence of the surface-active macromolecules. Such a minimization on the fouling effect of surfactant was in agreement with the observed good antifouling ability of an IL constructed carbon composite electrode [14,24,25].

Table 1 Normalized current, $I_{\mathrm{p}} / I_{\text {pmax }}$, expressed as a percentage, for $30.0 \mu \mathrm{g} \mathrm{L}{ }^{-1} \mathrm{Cd}(\mathrm{II})$ and $\mathrm{Pb}(\mathrm{II})$ with different concentrations of surfactants (mg $\mathrm{L}^{-1}$ ) obtained from the BONPs-IL-CPE and BONPs-PO-CPE

\begin{tabular}{|c|c|c|c|c|c|c|c|c|c|c|}
\hline \multirow{3}{*}{ Metal ion } & \multirow{3}{*}{ Electrode } & \multicolumn{9}{|c|}{$I_{\mathrm{p}} / I_{\mathrm{pmax}}(\%)$} \\
\hline & & \multicolumn{3}{|c|}{ Triton X-100 $\left(\mathrm{mg} \mathrm{L}^{-1}\right)$} & \multicolumn{3}{|c|}{ SDS $\left(\mathrm{mg} \mathrm{L}^{-1}\right)$} & \multicolumn{3}{|c|}{ CTAB $\left(\mathrm{mg} \mathrm{L}^{-1}\right)$} \\
\hline & & 5 & 10 & 20 & 5 & 10 & 20 & 5 & 10 & 20 \\
\hline $\mathrm{Cd}(\mathrm{II})$ & BONPs-IL-CPE & 81 & 72 & 58 & 89 & 82 & 68 & 76 & 64 & 51 \\
\hline \multirow{2}{*}{$\mathrm{Pb}(\mathrm{II})$} & BONPs-IL-CPE & 79 & 70 & 57 & 88 & 82 & 67 & 77 & 66 & 53 \\
\hline & BONPs-PO-CPE & 72 & 62 & 51 & 82 & 71 & 62 & 71 & 59 & 47 \\
\hline
\end{tabular}


Table 2 Recovery test for the determination of $\mathrm{Cd}(\mathrm{II})$ and $\mathrm{Pb}(\mathrm{II})$ in extracted milk samples

\begin{tabular}{|c|c|c|c|c|c|c|}
\hline \multirow{2}{*}{ Sample No. } & \multicolumn{3}{|c|}{$\mathrm{Cd}(\mathrm{II})$} & \multicolumn{3}{|c|}{$\mathrm{Pb}(\mathrm{II})$} \\
\hline & Added $\left(\mu \mathrm{g} \mathrm{L}^{-1}\right)$ & Found $\left(\mu \mathrm{g} \mathrm{L}^{-1}\right)$ & Recovery (\%) & Added $\left(\mu \mathrm{g} \mathrm{L}^{-1}\right)$ & Found $\left(\mu \mathrm{g} \mathrm{L}^{-1}\right)$ & Recovery (\%) \\
\hline \multirow[t]{2}{*}{1} & 20.0 & $19.63 \pm 1.03^{a)}$ & 98.15 & 20.0 & $19.55 \pm 0.97$ & 97.75 \\
\hline & 50.0 & $48.06 \pm 1.98$ & 96.12 & 50.0 & $47.93 \pm 1.64$ & 95.86 \\
\hline \multirow[t]{2}{*}{2} & 25.0 & $26.17 \pm 1.21$ & 104.68 & 25.0 & $25.73 \pm 1.06$ & 102.92 \\
\hline & 60.0 & $63.08 \pm 2.02$ & 105.13 & 60.0 & $62.86 \pm 1.91$ & 104.77 \\
\hline \multirow[t]{2}{*}{3} & 30.0 & $31.15 \pm 1.85$ & 103.83 & 30.0 & $30.68 \pm 1.24$ & 102.27 \\
\hline & 80.0 & $84.98 \pm 2.17$ & 106.23 & 80.0 & $83.57 \pm 2.25$ & 104.46 \\
\hline
\end{tabular}

a) Value is the mean of six measurements \pm standard deviation.

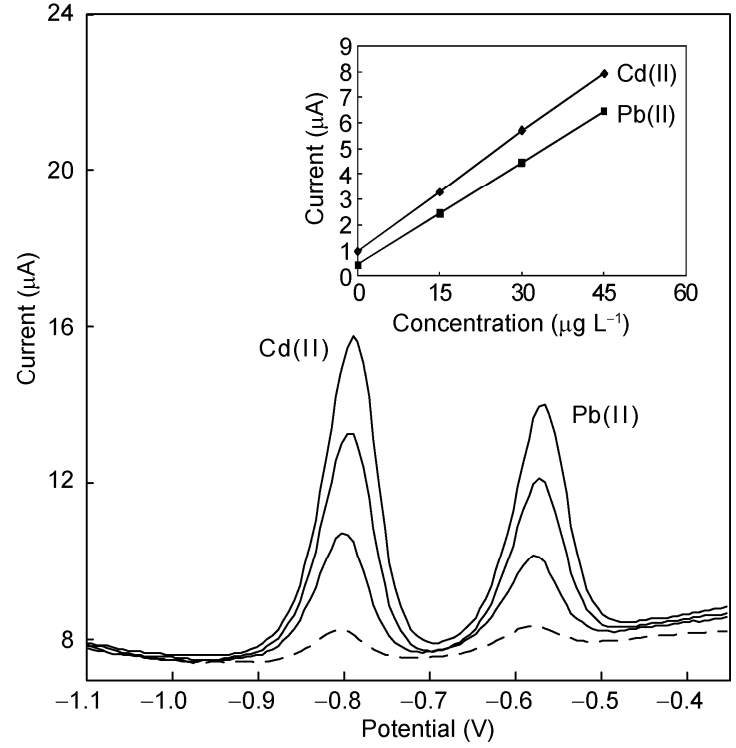

Figure 6 SWASV of the extracted milk sample prepared with $5.0 \mu \mathrm{g} \mathrm{L}^{-1}$ $\mathrm{Cd}(\mathrm{II})$ and $\mathrm{Pb}$ (II) (dashed line) together with three SWASVs recorded after consecutive standard additions of $15.0 \mu \mathrm{g} \mathrm{L} \mathrm{L}^{-1} \mathrm{Cd}$ (II) and $\mathrm{Pb}$ (II) (full lines). Inset shows the corresponding standard addition plot. Other conditions are as in Figure 2.

To evaluate the feasibility of our composite electrode for routine analysis, the BONPs-IL-CPE was used to detect heavy metal ions in extracted milk samples. Before the determination, the extracted milk samples were prepared by dosing to $5.0 \mu \mathrm{g} \mathrm{L}^{-1} \mathrm{Cd}(\mathrm{II})$ and $\mathrm{Pb}$ (II). The determination of these two metal ions at the BONPs-IL-CPE was performed by standard addition method. A typical analysis from these tests is shown in Figure 6, the square wave anodic stripping response of the prepared sample is shown with three consecutive standard additions of $15.0 \mu \mathrm{g} \mathrm{L}^{-1} \mathrm{Cd}(\mathrm{II})$ and $\mathrm{Pb}(\mathrm{II})$. The feasibility of the developed electrode for the determination of heavy metal ions in extracted milk sample was further examined by the recovery test. The results (summarized in Table 2) showed that the BONPs-IL-CPE possessed reasonable sensitivity and produced satisfactory recovery results with an average recovery of $102.36 \%$ for $\mathrm{Cd}(\mathrm{II})$ and $101.34 \%$ for $\mathrm{Pb}(\mathrm{II})$ and the relative standard deviation for both metal ions was less than $6.7 \%$. All of these results indicated that the present BONPs-IL-CPE could be used for the detection of trace heavy metal ions in food samples.

\section{Conclusions}

In this work, a novel composite electrode for heavy metal ions sensing made from BONPs, IL and graphite powder was developed. Combining the high conductivity and good antifouling capacity of OPFP and the unique features of BONPs, the developed electrode exhibited very good analytical performance. Several experimental parameters were optimized and the influence of surfactants on the stripping behavior was investigated. Our composite electrode exhibited a wide linear response range from 3.0 to $30.0 \mu \mathrm{g} \mathrm{L}^{-1}$ for both metal ions, and lower detection limit of 0.15 and 0.21 $\mu \mathrm{g} \mathrm{L}^{-1}$ for $\mathrm{Cd}(\mathrm{II})$ and $\mathrm{Pb}(\mathrm{II})$, respectively. In addition, the proposed electrode was applied to detect trace metal ions in milk samples with satisfactory results. This work introduces a highly sensitive, reproducible and stable heavy metal ion sensor by using nanomaterials and an IL modified carbon composite electrode, which holds great promise for wide application in environmental and food analysis.

This work was supported by the National High Technology Research and Development Program of China (2011AA100704).

1 Grześ I M. Ants and heavy metal pollution-A review. Eur J Soil Biol, 2010, 46: 350-355

2 Wu G, Kang H B, Zhang X Y, et al. A critical review on the bio-removal of hazardous heavy metals from contaminated soils: Issues, progress, eco-environmental concerns and opportunities. J Hazard Mater, 2010, 174: 1-8

3 Wei B G, Yang L S. A review of heavy metal contaminations in urban soils, urban road dusts and agricultural soils from China. Microchem J, 2010, 94: 99-107

4 Puschenreiter M, Horak O, Friesl W, et al. Low-cost agricultural measures to reduce heavy metal transfer into the food chain -A review. Plant Soil Environ, 2005, 51: 1-11

5 Brainina K Z, Malakhova N A, Stojko N Y. Stripping voltammetry in environmental and food analysis. Fresenius J Anal Chem, 2000, 368: 307-325

6 Karadjova I, Izgi B, Gucer S. Fractionation and speciation of $\mathrm{Cu}, \mathrm{Zn}$ and $\mathrm{Fe}$ in wine samples by atomic absorption spectrometry. Spectroc Acta Pt B, 2002, 57: 581-590

7 Chuparina E V, Aisueva T S. Determination of heavy metal levels in medicinal plant Hemerocallis minor Miller by X-ray fluorescence spectrometry. Environ Chem Lett, 2011, 9: 19-23

8 Alison M G, Andrew C C, Geoffrey R S. Determination of free and total copper and lead in wine by stripping potentiometry. Fresenius $\mathrm{J}$ Anal Chem, 1997, 358: 711-717

9 Economou A. Bismuth-film electrodes: Recent developments and 
potentialities for electroanalysis. TrAC Trends Anal Chem, 2005, 24: 334-340

10 Tesarovaa E, Baldrianovaa L, Hocevar S B, et al. Anodic stripping voltammetric measurement of trace heavy metals at antimony film carbon paste electrode. Electrochim Acta, 2009, 54: 1506-1510

$11 \mathrm{Wu} \mathrm{H}$ P. Nature and stability of mercury thin films on glassy carbon electrodes under fast-scan anodic stripping voltammetry. Anal Chem, 1994, 66: 3151-3157

12 Wang J, Lu J M, Hocevar S B, et al. Bismuth-coated carbon electrodes for anodic stripping voltammetry. Anal Chem, 2000, 72: 3218-3222

13 Agnieszka K, Andrzej B. Bismuth film electrode for adsorptive stripping voltammetry - electrochemical and microscopic study. Electrochem Commun, 2004, 6: 99-104

14 Ping J F, Wu J, Ying Y B, et al. Evaluation of trace heavy metal levels in soil samples using an ionic liquid modified carbon paste electrode. J Agric Food Chem, 2011, 59: 4418-4423

15 Švancara I, Baldrianová L, Tesařová E, et al. Recent advances in anodic stripping voltammetry with bismuth-modified carbon paste electrodes. Electroanalysis, 2006, 18: 177-185

16 Kadaraa, R O, Tothill I E. Development of disposable bulk-modified screen-printed electrode based on bismuth oxide for stripping chronopotentiometric analysis of lead (II) and cadmium (II) in soil and water samples. Anal Chim Acta, 2008, 623: 76-81

17 Królicka A, Pauliukaitė R, Švancara I, et al. Bismuth-film-plated carbon paste electrodes. Electrochem Commun, 2002, 4: 193-196

18 Hwang G, Han W, Park J, et al. An electrochemical sensor based on the reduction of screen-printed bismuth oxide for the determination of trace lead and cadmium. Sens Actuators B, 2008, 135: 309-316

19 Švancara I, Vytřas K, Kalcher K, et al. Carbon paste electrodes in facts, numbers, and notes: A review on the occasion of the 50-years jubilee of carbon paste in electrochemistry and electroanalysis. Electroanalysis, 2009, 21: 7-28

20 Arduini F, Calvo J Q, Amine A, et al. Bismuth-modified electrodes for lead detection. TrAC Trends Anal Chem, 2010, 29: 1295-1304
21 Kadara R O, Jenkinson N, Banks C E. Disposable bismuth oxide screen printed electrodes for the high throughput screening of heavy metals. Electroanalysis, 2009, 21: 2410-2414

22 Lee $\mathrm{G}$, Lee $\mathrm{H}$, Rhee $\mathrm{C}$. Bismuth nano-powder electrode for trace analysis of heavy metals using anodic stripping voltammetry. Electrochem Commun, 2007, 9: 2514-2518

23 Liu H T, He P, Li Z Y, et al. An ionic liquid-type carbon paste electrode and its polyoxometalate-modified properties. Electrochem Commun, 2005, 7: 1357-1363

24 Ping J F, Ru S P, Fan K, et al. Copper oxide nanoparticles and ionic liquid modified carbon electrode for the non-enzymatic electrochemical sensing of hydrogen peroxide. Microchim Acta, 2010, 171: 117-123

25 Maleki H, Safavi A, Tajabadi F. High-performance carbon composite electrode based on an ionic liquid as a binder. Anal Chem, 2006, 78: 3820-3826

26 Ping J F, Wu J, Ru S P, et al. Triphenylamine as a conductive solid material for fabricating carbon electrodes. Microchim Acta, 2011, 172: $241-245$

27 Safavi A, Maleki N, Honarasa F, et al. Molecular wires as a new class of binders in carbon composite electrodes. Electrochem Commun, 2009, 11: 1113-1115

28 Sau T K, Rogach A L. Nonspherical noble metal nanoparticles: colloid-chemical synthesis and morphology control. Adv Mater, 2009, 21: $1-24$

29 Lahiff E, Lynam C, Gilmartin N, et al. The increasing importance of carbon nanotubes and nanostructured conducting polymers in biosensors. Anal Bioanal Chem, 2010, 398: 1575-1589

30 Campbell F W, Compton R G. The use of nanoparticles in electroanalysis: an updated review. Anal Bioanal Chem, 2010, 396: 241-259

31 Tokusoğlu Ö, Aycan S, Akalin S, et al. Simultaneous differential pulse polarographic determination of cadmium, lead, and copper in milk and dairy products. J Agric Food Chem, 2004, 52: 1795-1799

32 Pauliukaite R, Metelka R, Švancara I, et al. Carbon paste electrodes modified with $\mathrm{Bi}_{2} \mathrm{O}_{3}$ as sensors for the determination of $\mathrm{Cd}$ and $\mathrm{Pb}$. Anal Bioanal Chem, 2002, 374: 1155-1158

Open Access This article is distributed under the terms of the Creative Commons Attribution License which permits any use, distribution, and reproduction in any medium, provided the original author(s) and source are credited. 